\title{
Variations in Measurements of the Aortic Knob in the Chest Radiograph in Normal and Hypertensive Subjects
}

\author{
Prakash Kayastha ${ }^{1}$, Sharma Paudel ${ }^{1}$, Sundar Suwal ${ }^{1}$, Binaya Adhikari ${ }^{1}$, Mukunda Prasad \\ Humagain', Bhawan Thapa Magar², Krishna Prasad Adhikary³
}

\section{Author Info:}

${ }^{1}$ Department of Radiology and Imaging, Tribhuvan University Teaching Hospital, Institute of Medicine, Kathmandu, Nepal

2 Department of Radiology, Patan Academy of Health Sciences, Lalitpur, Nepal

${ }^{3} \mathrm{Nepal}$ Medical Council

\section{Corresponding Author:}

Dr. Sharma Paudel, MD

Associate Professor; Tribhuvan University Teaching Hospital, Maharajgunj Medical Campus, Institute of Medicine, Kathmandu, Nepal Email: sharmapaudel@gmail.com

\begin{abstract}
Background: Aortic knob enlarges in many cardiovascular disorders including hypertension. It can be easily evaluated in chest radiographs. The study was carried out to document and analyze measurements of aortic knob in normal and hypertensive population in chest radiograph.
\end{abstract}

Methods: This descriptive cross-sectional study was performed in the Department of Radiology and Imaging, Tribhuvan University Teaching Hospital (TUTH) and Manmohan Cardiothoracic Vascular and Transplant Center (MCVTC) from July to October 2019. Postero-anterior (PA) chest radiographs of 200 individuals (100 normal and 100 hypertensives) between the age of 18 to 70 years were evaluated. Width of aortic knob (AKW), straight length of aortic knob (AKS), curved length of aortic knob (AKC) and aortic knob index (AKI) were measured. Aortic knob index (AKI) was determined from AKC divided by AKS.

Results: The mean aortic knob index (AKI) for male and female were $1.24 \pm 0.06$ and $1.20 \pm 0.07$ respectively and the total mean aortic knob index (AKI) was $1.22 \pm 0.07$ in normal population. In hypertensive population, aortic knob index (AKI) was $1.49 \pm 0.095$ and $1.42 \pm 0.04$ in male and female respectively. Total aortic knob index (AKI) for hypertensive population was $1.45 \pm 0.083$. Aortic knob index in hypertensive population was significantly higher than that of normal population. Mean aortic knob index (AKI) in male was significantly higher than that in female in both normal and hypertensive population $(p<0.05)$.

Conclusion: Aortic knob index (AKI), the index for aortic diameter, was higher in hypertensive population and male. Thus, simple measurement of aortic knob in PA chest $\mathrm{x}$-ray may help in predicting cardiovascular disorder.

Keywords: Aortic knob, Chest radiograph, Hypertensive population, Measurements

QR Code
How to cite this article in Vancouver Style?
Kayastha P, Paudel S, Suwal S, Adhikari B, Humagain MP, Thapa Magar B, Adhikary KP. Measurements of the Aortic
Knob in the Chest Radiograph. Europasian J Med Sci.2020;2(2):92-96. https://doi.org/10.46405/ejms.V2i2.212




\section{INTRODUCTION}

The postero-anterior (PA) chest radiograph is one of the most common imaging modalities for evaluation of the heart and lungs. ${ }^{1}$ Aortic knob or knuckle (AK) forms the superior most convex arc of the left border of the cardiac silhouette on a PA chest radiograph. The aortic knob represents the distal-most portion of the aortic arch, where it turns downwards to become the descending aorta. The medial border of the arch of the aorta cannot be identified in the $\mathrm{x}$-ray as it blends with the shadows of the mediastinum. As the aortic arch abuts left lung laterally, it is seen as the lateral bulge.,3 The aortic knob is the portion of the aortic arch that is seen in a postero-anterior chest radiograph. Increase in the transverse diameter of the arch of aorta has been associated with hypertension and cardiac dysfunction. ${ }^{2,4}$ The aortic knob can be enlarged due to increased pressure flow in aorta or changes in the elasticity of its wall in various conditions like systemic hypertension, cystic medial necrosis of aorta or aortic dissection. Prominence of aortic knob is also seen in aortic stenosis, coarctation and aneurysm. Systemic hypertension is a common condition where aortic knob size increases. The enlargement of aortic knob though not specific but still an easily available and initial investigating tool to predict the cardiac malfunction in the outdoor practice. It can guide for appropriate further investigations and treatment. . $^{3-5}$ There is relatively lack of data of the size of the aortic knob in Nepali population, so in this study we designed to find out the normal diameter of the aortic knob in Nepalese population and compare it with hypertensive patients.

\section{MATERIALS AND METHODS}

A descriptive cross-sectional study was conducted in the Department of Radiology and Imaging Tribhuvan University Teaching Hospital, and Manmohan Cardio Thoracic and Vascular Transplant Center, Kathmandu, Nepal during the period from July to October 2019.

A total of 200 chest radiographs from 100 normotensive and 100 hypertensive individuals between the age of 18 to 70 years were randomly selected and evaluated. Radiographs of both males and females were included in the study. Portable radiographs, radiographs with rotation, radiographs of individuals with heart diseases or pathology detected in the radiographs were excluded. All the radiographs were performed in posterio-anterior view by using Hitachi medical corporation (Z4-L3TY) x-ray machine with capacity of 150 kilovoltage $(\mathrm{kV})$ and 500 miliampare $(\mathrm{mA})$.

The measurements were carried out with the measuring tools available on the software of the computed radiography system. All the measurements were carried out with one and half time magnification. The parameters measured were aortic knob width (AKW), straight length of aortic knob (AKS), curved length of aortic knob (AKC) and aortic knob index (AKI). The AKW is the striaght horizontal line drawn from midline of the body to lateral aspect of the aortic knob, AKS is the straight vertical line drawn from superior point of aortic knob to inferior margin of the aortic knob and AKC is curved length drawn from superior portion to inferior margin along the lateral aspect of the aortic knob (Figure 1). AKI is the ratio of AKC to AKS (AKC/AKS).

Figure 1: Chest radiograph showing different

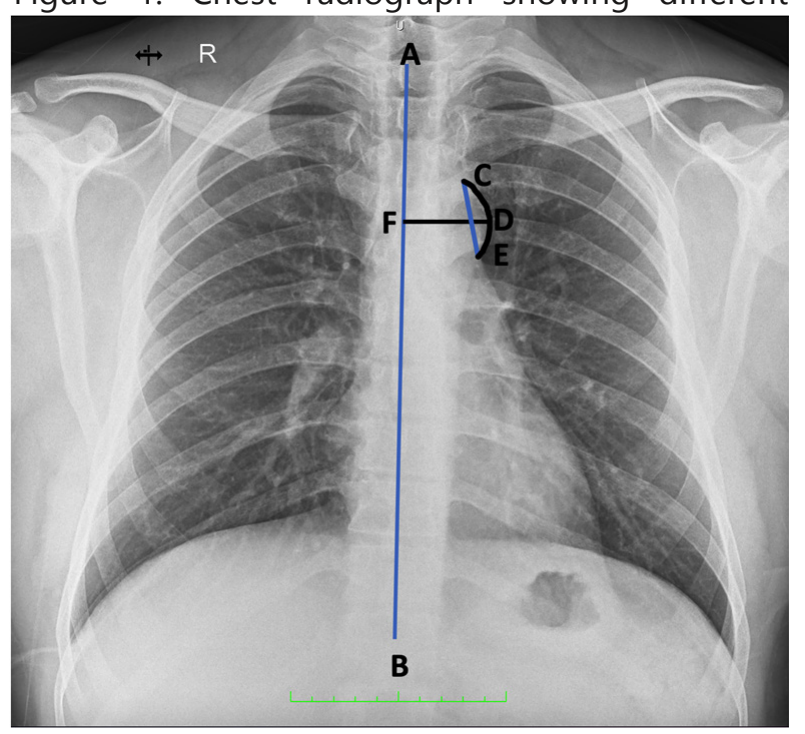

measurements of aortic knob

$A B=$ Midline; $D F=$ Width of aortic knob (AKW)

$C E=$ Straight length of aortic knob (AKS)

$C D E=$ Curved length of the aortic knob (AKC)

Statistical analysis was carried out with the help of IBM-SPSS 20.0 (IBM Corporation, Armonk, NY, USA) and Microsoft Excel version 12. Mean and standard deviation (SD) of the parameters of aortic knob measurements mentioned above were obtained. Gender difference of these parameters in normal and hypertensive subjects were evaluated with $T$ value and degree of freedom (Df). Independent sample t-test was used for correlation of AKI in 
normal subjects and hypertensive subjects. $\mathrm{P}<0.05$ was considered to be statistically significant.

\section{RESULTS}

The data was collected from total 200 patients (100 normotensive and 100 hypertensive) of 18 to 70 years of age. Among 200 patients, 104 were female and 96 were male with female: male ratio of 1.08:1.

\section{Normal population}

The mean values of width of aortic knob for male in chest radiograph was $2.822 \pm 0.21 \mathrm{~cm}$ and that for female was $2.75 \pm 0.1741 \mathrm{~cm}$ in normal population [Table 1]. Though the aortic knob width in male in normal population was higher than in female, the difference was not statistically significant $(p=$ 0.105) [Table 2].

Table 1: Mean and SD of aortic knob from width of aortic knob (AKW), straight length of aortic knob (AKS), aortic knob index $(A K I))$ in normal population

\begin{tabular}{lllllll}
\hline Sex & AKW $(\mathrm{cm})$ & & AKS $(\mathrm{cm})$ & & AKI \\
& Mean & SD & Mean & SD & Mean & SD \\
\hline Male $(\mathrm{n}=46)$ & 2.822 & 0.2132 & 2.8666 & 0.2042 & 1.2452 & 0.0666 \\
Female $(\mathrm{n}=54)$ & 2.75 & 0.1741 & 2.8176 & 0.196 & 1.200 & 0.0761 \\
Total $(\mathrm{n}=100)$ & 2.786 & 0.1936 & 2.8421 & 0.2001 & 1.22 & 0.074 \\
\hline
\end{tabular}

Table 2: Test of significant difference between male and female width of aortic knob (AKW), straight length of aortic knob (AKS), aortic knob index (AKI) in normal population

\begin{tabular}{ccccc}
\hline Parameter & Mean difference $(\mathrm{cm})$ & T Value & DF(degrees of freedom) & $p$ value \\
\hline AKW & 0.065 & 1.65 & 98 & 0.105 \\
AKS & 0.0493 & 1.234 & 98 & 0.219 \\
AKI & 0.0446 & 3.10 & 98 & 0.003
\end{tabular}

Table 3: The average value of mean and standard deviation of aortic knob width (AKW), straight length of aortic knob (AKS) and aortic knob index (AKI)) in the hypertensive population

\begin{tabular}{ccccccc}
\hline Sex & \multicolumn{2}{c}{ AKW $(\mathrm{cm})$} & \multicolumn{2}{c}{ AKS $(\mathrm{cm})$} & & AKI \\
& Mean & SD & Mean & SD & Mean & SD \\
\hline Male $(n=50)$ & 3.3121 & 0.1755 & 2.9432 & 0.177 & 1.492 & 0.095 \\
Female $(n=50)$ & 3.2025 & 0.1359 & 2.93 & 0.133 & 1.4223 & 0.0493 \\
Total $(n=100)$ & 3.2573 & 0.155 & 2.936 & 0.1555 & 1.45 & 0.083 \\
\hline \hline
\end{tabular}

Table 4: Test of significant difference between male and female width of aortic knob (AKW), straight length of aortic knob $(A K S)$, aortic knob index (AKI) in the hypertensive population

\begin{tabular}{lcccc}
\hline \multicolumn{1}{c}{ Parameter } & Mean difference $(\mathrm{cm})$ & T value & Df & P value \\
\hline AKW & 0.1095 & 3.483 & 98 & 0.001 \\
AKS & 0.00295 & 0.095 & 98 & 0.924 \\
AKI & 0.074 & 4.63 & 98 & 0.000 \\
\hline
\end{tabular}


Table 5: Male and female aortic knob index (AKI) in hypertensive population $(n=100)$

\begin{tabular}{|c|c|c|c|c|c|c|}
\hline \multirow{2}{*}{ Subject } & \multirow{2}{*}{$\mathrm{N}$} & \multirow{2}{*}{ Mean $^{ \pm}$SD } & \multirow{2}{*}{ Median } & \multirow{2}{*}{ Range } & \multicolumn{2}{|c|}{ 95\% Confidence Interval } \\
\hline & & & & & Lower & Upper \\
\hline Male & 50 & $1.4952 \pm 0.095$ & 1.4844 & $1.97-1.34$ & 1.47 & 1.52 \\
\hline Female & 50 & $1.420 \pm 0.046$ & 1.4221 & $1.54-1.30$ & 1.41 & 1.43 \\
\hline
\end{tabular}

hypertensive population was significantly higher than in females $(p<0.05)$ [Table 4].

The mean value of straight length of aortic knob (AKS) for males was $2.94 \pm 0.17 \mathrm{~cm}$ and that of female was $2.93 \pm 0.13 \mathrm{~cm}$ in hypertensive population [Table 3]. The straight length of aortic knob in males was higher than in females. However it was not statistically significant $(p=0.924)$ [Table 4].

The mean value of aortic knob index (AKI) for male was $1.49 \pm 0.095$ and that of female was $1.42 \pm 0.0493$ in hypertensive population [Table 3]. The aortic knob index $(\mathrm{AKI})$ in male was significantly higher than in female $(p<0.05)$ [Table 4 ].

Mean aortic knob index (AKI) in normal population was $1.22 \pm 0.07$ and Mean aortic knob index for hypertensive population was $1.45 \pm 0.08$. Aortic knob index in hypertensive population was significantly higher than that of normal population $(p<0.05)$ and the overall aortic knob index in male was also significantly higher than females $(p<0.05)$.

\section{DISCUSSION}

The postero-anterior (PA) chest radiograph is one of the common and routine imaging modalities for evaluation of the heart. But anatomical variation of aortic knob is not evaluated well in clinical practice. Increase in the transverse diameter of the arch of aorta has been associated with hypertension and cardiac dysfunction. ${ }^{6}$ So, simple evaluation of aortic knob can be predicting factor for cardiovascular disease.

Mean AKW in a study done by Lee et al ${ }^{6}$ was $34.21 \pm 4.78 \mathrm{~mm}$ and $30.03 \pm 4.98 \mathrm{~mm}$ in men and women respectively, which is higher than the mean in our study, however, they also found higher AKW in male than female similar to our study. However, in a study done in India by Ray et al mean AKW was similar to our study $(3.10 \pm 3.34 \mathrm{~cm}$ in men and $3.08 \pm 3.90 \mathrm{~cm}$ in women). ${ }^{7}$ They also found higher AKW in male than female as in our study. Studies performed by Obikili and Okoye ${ }^{8}$; Anyanwu et $\mathrm{al}^{3}$ also showed higher $\mathrm{AKW}$ in male compared to female. In contrast to our study, mean AKW was independent of sex in a study done by Afsar et al in Turkey. ${ }^{9}$ However, they found higher AKW with higher systolic blood pressure and our study also showed higher AKW in hypertensive patients. Rayner et al also found higher aortic knob width in hypertensives corroborating our findings. ${ }^{10}$

Shankar et $\mathrm{al}^{2}$ found lower AKI in male $(1.13 \pm 0.11)$ than in female $(1.16 \pm 0.11)$, in contrast to our study as our study showed significantly higher AKI in male. However, the difference was not significant in the study done by Shankar et al which may be due to non-visualization of aortic knob in eight out of 77 males. AKI, a ratio of AKC to AKS, was higher in hypertensives in our study, supporting above measurements (AKW). Increased pressure of blood flow in the ascending aorta and aortic arch in hypertensive patients might be the cause of enlargement of aortic arch. As AKI provides quantitative estimate of aortic knob and is a ratio independent of absolute measurements, it will be better suited for comparisons of aortic knob in different populations.

\section{CONCLUSION}

Aortic knob index (AKI) in hypertensive population and male was higher than in normal population, suggesting increased their aortic arch diameter. Thus simple measurement of aortic knob in PA chest $\mathrm{x}$-ray may help in predicting cardiovascular disorder.

\section{REFERENCES}

1. Sutton D, Gregson RHS. Arteriography and interventional angiography. In: Sutton D (ed). Textbook of Radiology and Imaging, Vol 1, 7th ed (2003). Churchill Livingstone, Edinburgh, pp 427.

2. Shankar N, Veeramani R, Ravindranath $R$, Philip B. Anatomical variations of the aortic knob in chest radiographs. European Journal of Anatomy. 2010;14(1):25-30.

3. Felson B. A review of over 30,000 normal chest roentgenograms. In: Chest Roentgenology. WB Saunders, Philadelphia (1973), pp 495.

4. Anyanwu GE, Anibeze CIP, Akpuaka FC. Transverse aortic arch diameters and relationship with heart size of Nigerians within the south east. Biomedical Research. 2007;18(2): 115-118. 
5. Ikeme AC, Ogakwu MA, Nwakonobi FA. The significance of the enlargement of the aortic shadow in adult Nigerians. African journal of medicine and medical sciences. 1976;5(3):195-9.

6. Lee EJ, Han JH, Kwon KY, Kim JH, Han KH, Sung SY, Hong SR. The Relationship between Aortic Knob Width and Metabolic Syndrome. Korean Journal of Family Medicine, 2018;39(4),253-259. https://doi. org $/ 10.4082 / \mathrm{kjfm} .17 .0038$

7. Ray A, Mandal D, Kundu P, Manna S and Mandal $\mathrm{S}$. Aortic knob diameter in chest $\mathrm{X}$-ray and its relation with age, heart diameter and transverse diameter of thorax in a population of Bankura District of West Bengal, India: a cross sectional study. Journal of Evolution of Medical and Dental Sciences. 2014;3(31):8595-600. https://doi. org/10.14260/jemds/2014/3092

8. Obikili EN, Okoye IJ. Aortic arch diameter in frontal chest radiographs of a normal Nigerian population. Nigerian Journal of Medicine: Journal of the National Association of Resident Doctors of Nigeria. 2004;13(2):171-174.

9. Afsar B, Saglam M, Yuceturk C, Agca E. The relationship between aortic knob width and various demographic, clinical, and laboratory parameters in stable hemodialysis patients. Saudi J Kidney Dis Transpl [serial online] 2014;25:1178-85. https://doi. org/10.4103/1319-2442.144250 [Full Text]

10. Brian LR, Hillel G, Lionel HO. The chest radiograph: A useful investigation in the evaluation of hypertensive patients. American Journal of Hypertension. 2004;17(6):507-510. https://doi.org/10.1016/j. amjhyper.2004.02.012 